\title{
MedChemComm
}

CrossMark $<$ click for updates

Cite this: Med. Chem. Commun., 2016, 7, 1604

Received 11th April 2016, Accepted 5th June 2016

DOI: 10.1039/c6md00199h

www.rsc.org/medchemcomm

\section{Pro-apoptotic and pro-differentiation induction by 8-quinolinecarboxaldehyde selenosemicarbazone and its Co(III) complex in human cancer cell linestt:}

\author{
Nenad R. Filipović, a Snežana Bjelogrlić, ${ }^{\mathrm{b}}$ Gustavo Portalone, ${ }^{\mathrm{c}}$ Sveva Pelliccia, \\ Romano Silvestri, ${ }^{d}$ Olivera Klisurić, ${ }^{e}$ Milan Senćanski, ${ }^{f}$ Dalibor Stanković, ${ }^{g}$ \\ Tamara R. Todorović ${ }^{\star h}$ and Christian D. Muller ${ }^{\star i}$
}

\begin{abstract}
8-Quinolinecarboxaldehyde selenosemicarbazone (H8qasesc) and its octahedral Co(III) complex were characterized by single crystal X-ray diffraction analysis, spectroscopy methods and cyclic voltammetry. The antineoplastic activity of the ligand and the complex has been assessed on an acute monocytic leukemia cell line (THP-1) and AsPC-1 cancer stem cell (CSC) line derived from a patient suffering from pancreatic adenocarcinoma, with cisplatin (CDDP) as a reference compound. Evaluation involved determination of pro-apoptotic activity, changes in cell cycle distribution, the role of caspase activation in the process of cell death, and the ability of the investigated compounds to challenge reprogramming of the CSC phenotype. Compared to CDDP, treatment with H8qasesc induced a higher apoptotic response in both investigated cell lines. Apoptosis triggered by H8qasesc was highly caspase-dependent but did not include activation of either caspase-8 or -9 . According to cell cycle changes H8qasesc delayed the transition of cells during DNA replication but in a manner different from that of CDDP. The ligand did not show nuclease activity on pUC19 plasmid, while docking studies disclosed that it does not have intercalating properties. Treatment of THP-1 cells with the Co(III) complex resulted in a strong toxic response, whereas cell death in the treated AsPC-1 line was not achieved for $24 \mathrm{~h}$. Additionally, the complex concentration-dependently digested plasmid DNA which might be the cause of its cytotoxic activity. Finally, H8qasesc successfully initiated reprogramming of the CSC phenotype in the AsPC-1 cell line.
\end{abstract}

\section{Introduction}

Selenosemicarbazones are Schiff bases obtained by the condensation reaction of carbonyl compounds and selenosemicarbazides. They showed antiparasitic, ${ }^{1}$ antifungal $^{2,3}$ antibacterial, $^{3-6}$ antimalarial,,$^{7-10}$ anticancer, ${ }^{3,7,10-23}$ antioxidant $^{3,14}$ and antidiabetic ${ }^{14}$ activity. In order to obtain more active species, complexes of $\mathrm{Pt}(\mathrm{II}), \mathrm{Pd}(\mathrm{II}), \mathrm{Zn}(\mathrm{II}), \mathrm{Cd}(\mathrm{II})$,
$\mathrm{Au}(\mathrm{I}), \mathrm{Ni}(\mathrm{II}), \mathrm{Co}(\mathrm{III}), \mathrm{Ga}(\mathrm{III}), \mathrm{Sn}$ (IV) and $\mathrm{Cu}(\mathrm{II})$ have been prepared and tested against malaria ${ }^{10,24,25}$ and microorganisms ${ }^{3-5}$ as well as cancer cell lines. ${ }^{3,11,16-23,26}$ As a result of such an approach, metal complexes with activities better than those of the corresponding ligands have been developed. . $^{3,19-23,26}$

Despite the fact that investigation of the biological activity of selenosemicarbazones started in the late fifties, apart from our research, up to now there are only three publications in

\footnotetext{
${ }^{a}$ Faculty of Agriculture, University of Belgrade, Nemanjina 6, Belgrade, Serbia

${ }^{b}$ National Cancer Research Center of Serbia, Pasterova 14, Belgrade, Serbia

${ }^{c}$ Dipartimento di Chimica, Sapienza Universita di Roma, Piazzale Aldo Moro 5, I-00185 Roma, Italy

${ }^{d}$ Dipartimento di Chimica e Tecnologie del Farmaco, Sapienza Universita di Roma, Piazzale Aldo Moro 5, I-00185 Roma, Italy

${ }^{e}$ Department of Physics, Faculty of Sciences, University of Novi Sad, Trg Dositeja Obradovića 4, Novi Sad, Serbia

${ }^{f}$ Center for Multidisciplinary Research, Institute of Nuclear Sciences "Vinča", University of Belgrade, Belgrade, Serbia

${ }^{g}$ Innovation Center of the Faculty of Chemistry, University of Belgrade,

Studentski trg 12-16, Belgrade, Serbia

${ }^{h}$ Faculty of Chemistry, University of Belgrade, Studentski trg 12-16, Belgrade,
}

\section{Serbia.E-mail: tamarat@chem.bg.ac.rs}

${ }^{i}$ Institut Pluridisciplinaire Hubert Curien, UMR 7178 CNRS Université de

Strasbourg, 67401 Illkirch, France.E-mail: cdmuller@unistra.fr

$\dagger$ The authors declare no competing interests.

$\ddagger$ Electronic supplementary information (ESI) available: The experimental section can be found in the supplementary materials (ESI). NMR (Fig. S1 and S2) and UVvis (Fig. S3) spectra; cyclic voltammograms (Fig. S4); packing diagrams (Fig. S5 and S6); sigmoidal dose-response curves (Fig. 7); activity on THP-1 cell line (Fig. S8 and S9); activity on caspase-8 and -9 (Fig. S10); the ligand H8qasesc and complex binding sites of HSA (Fig. S11); crystal data and selected geometrical parameters (Tables S1-S3); hydrogen bond and $\pi-\pi$ stacking interaction parameters (Table S4); interactions of HSA binding site (Table S5). CCDC 1471189 and 1401687. For ESI and crystallographic data in CIF or other electronic format see DOI: 10.1039/c6md00199h 
which mechanistic studies have been presented. ${ }^{11,23,27}$ First, Agrawal et al. showed that 5-hydroxy-2-formylpyridine selenosemicarbazone (5HPSe) caused marked inhibition of DNA synthesis in vitro, as measured by the incorporation of thymidine-methyl- ${ }^{3} \mathrm{H}, \quad 5-{ }^{3} \mathrm{H}$-cytidine or adenine- $8-{ }^{14} \mathrm{C}$ into DNA. ${ }^{11}$ It was shown that the primary target of 5HPSe was ribonucleotide reductase (RR). The recent study underlined the importance of reactive oxygen species (ROS) generation and the activation of a lysosomal apoptotic pathway through lysosomal membrane permeabilization (LMP) in the anticancer activity of 2-acetylpyridine 4,4-dimethyl-3-selenosemicarbazone and demonstrated lysosomal targeting as a novel mechanism of selenosemicarbazone antiproliferative activity. ${ }^{27}$

The biological properties of 2-formylpyridine selenosemicarbazone, 2-quinolinecarboxaldehyde selenosemicarbazone, 8-quinolinecarboxaldehyde selenosemicarbazone and 2,6diacetylpyridine bis(selenosemicarbazone) (Hfpsesc, Hqasesc, H8qasesc and $\mathrm{H}_{2}$ dapsesc, respectively, Scheme 1) were systematically examined by our group.,17-20,26 The monoselenosemicarbazones Hqasesc, Hfpsesc and H8qasesc had the ability to act as anti-proliferative agents, inducing apoptosis and cell cycle perturbations in different malignant cell lines, while bis(selenosemicarbazone) $\mathrm{H}_{2}$ dapsesc was far more active against normal than malignant cell lines, predominantly inducing necrotic cell death.,17-20,26 The ligand Hqasesc induced growth inhibition in several cancer cell lines, although $\mathrm{IC}_{50}$ values were 2-10 times higher compared to those of cisplatin (CDDP). Being mostly successful on human cervical adenocarcinoma (HeLa) cells, Hqasesc triggered a significant increase in a sub- $\mathrm{G}_{0} / \mathrm{G}_{1}$ cell population as compared to the non-treated control, which confirmed its ability to trigger apoptotic cell death. ${ }^{20}$ This ligand also caused a strong concentration-dependent apoptosis induction in acute monocytic leukemia (THP-1) cells, while in a pancreatic adenocarcinoma cell line (AsPC-1) it induced apoptosis only at the highest concentration. ${ }^{26}$ The ligand Hfpsesc was tested on a wide range of malignant cell lines, such as human breast adenocarcinomas (MB-453 and MB-361), human osteosarcoma (U2Os) and its CDDP-resistant sibling U2OS-Pt, HeLa cells, human melanoma (FemX), human colorectal adenocarcinoma (LS174), and murine melanoma (B16). ${ }^{19}$ Its ac- tivity was revealed to be phenotype specific, with stronger inhibition of cell growth than CDDP on MDA-361, LS-174, and B16 cells. In LS174, FemX and MDA-143 cell lines, treatment with Hfpsesc resulted in the accumulation of cells in the $S$ to $\mathrm{G}_{2} / \mathrm{M}$ phase, while for U2OS and U2OS-Pt, cells were accumulated exclusively in the $\mathrm{S}$ phase. The ligand H8qasesc showed the same degree of antiproliferative activity against the U251 cell line as that of CDDP, with a 20 times higher antioxidant potential when compared to vitamin $\mathrm{C}^{3}$

Preparation of $\mathrm{Pt}(\mathrm{II}), \mathrm{Pd}(\mathrm{II}), \mathrm{Cd}(\mathrm{II}), \mathrm{Ni}(\mathrm{II}), \mathrm{Co}$ (II) and $\mathrm{Zn}$ (II) complexes with Hqasesc and Hfpsesc as well as Pt(II) and Pd(II) complexes with H8qasesc resulted in compounds more potent than CDDP and the ligands themselves. ${ }^{3,17-20}$ In general, monoselenosemicarbazone complexes induced apoptosis in all investigated cell lines. ${ }^{3,17,19,20,26}$ In the case of bis(selenosemicarbazone) ligand $\mathrm{H}_{2}$ dapsesc and its $\mathrm{Cd}$ (II) and Zn(II) complexes, neither caspase activity nor ROS production was induced in treated cells. ${ }^{18}$ A more detailed mechanistic analysis of the action of the Cd complex of Hqasesc revealed that it causes cell cycle arrest in the $G_{0} / G_{1}$ stage, massive caspase activation and production of ROS. ${ }^{3}$ The $\mathrm{Zn}$ (II) complex of Hqasesc interfered with DNA replication, causing concentration-dependent apoptotic induction in THP-1 cells, which coincided with the arrest of mitotic division at the $S$ phase. $^{26}$ On the other hand, dramatically increased phosphorylation of extracellular receptor kinase, with a recorded release of cytochrome $\mathrm{C}$ and activation of p73 in HeLa and MDA-361 cells treated with Hfpsesc and its $\mathrm{Cd}(\mathrm{II}), \mathrm{Ni}$ (II) and $\mathrm{Zn}$ (II) complexes, was detected. ${ }^{17}$ The Ni(II) complex with Hfpsesc also showed potent anti-metastatic activity. ${ }^{16}$ Our studies have pointed out the importance of the nature of the metal ions in the mechanism of activity of selenosemicarbazone complexes.

Cobalt is particularly suitable for complexation with selenosemicarbazones since it is a biometal and already serves as a co-factor in a number of natural enzymes. ${ }^{28,29} \mathrm{In}$ our previous work we synthesized Co(III) complex with Hqasesc ligand, [Co(qasesc $\left.)_{2}\right] \mathrm{BF}_{4}$, which did not show promising anticancer activity. ${ }^{19}$ In this complex, the ligand Hqasesc was tridentately (NNSe) coordinated, with the formation of two 5-membered chelate rings. Here we present the synthesis
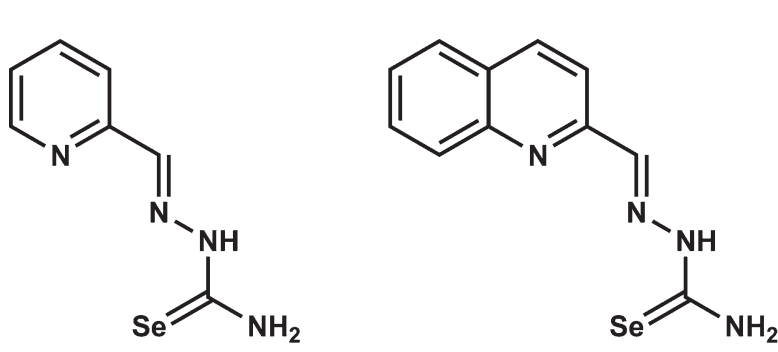

Hfpsesc
Hqasesc

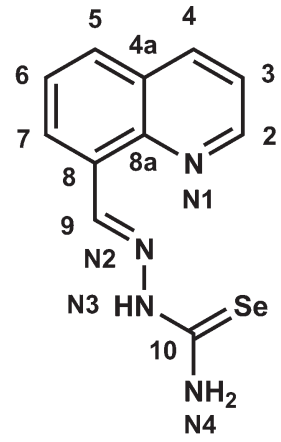

H8qasesc<smiles>C/C(=N\NC(N)=[Se])c1cccc(/C(C)=N/NC(N)=[Se])n1</smiles>

$\mathrm{H}_{2}$ dapsesc

Scheme 1 Structures of mono- and bis(selenosemicarbazone) ligands. 
and characterization of a novel Co(III) complex with H8qasesc ligand, a structural isomer of Hqasesc. Two isomers have the same mode of coordination, but H8qasesc is capable of forming one 5-membered and one 6-membered chelate ring. Our recent report indicates that chelate ring size may induce differences in the biological activity of metal complexes. ${ }^{30}$

In the current study, evaluation of the anticancer potency of H8qasesc and its Co(III) complex was carried out in order to investigate their pro-apoptotic activity on two malignant cell lines with pro-differentiation activity on cancer stem cells (CSCs). The human pancreatic adenocarcinoma cell line AsPC-1 is expressing epithelial-mesenchymal transition (EMT)-associated genes which promote tumor progression and metastasis, and this cell line is designated as a good cancer stem cell model. ${ }^{31}$ CSCs are rare immortal cells within a tumor, dividing rapidly unlike stem cells of healthy tissues and giving rise to resistance to therapy and tumor relapse. ${ }^{32}$ Results from experimental models and clinical studies showed that CSCs survive many commonly employed cancer treatments, giving them a high clinical relevance. Elimination of CSCs is set as the crucial need in the intention to cure the cancer. For this reason, we challenged our compounds against the AsPC- 1 cell line together with the THP-1 cell line to evaluate their ability to trigger apoptotic death and/or to induce differentiation.

\section{Results and discussion}

\subsection{Synthesis and characterization}

A cobalt(III) complex with $\mathrm{N}$-heteroaromatic selenosemicarbazone ligand H8qasesc has been synthesized. The complex was prepared by a template reaction starting from $\mathrm{Co}\left(\mathrm{ClO}_{4}\right)_{2}$ $\cdot 6 \mathrm{H}_{2} \mathrm{O}, 8 \mathrm{qa}$ and selenosemicarbazide (mole ratio $1: 2: 2$, respectively). The complex is soluble in $\mathrm{MeOH}, \mathrm{EtOH}, \mathrm{MeCN}$, DMF and DMSO at room temperature. Molar conductivity measurements showed that the obtained complex is a 1:1 type of electrolyte. The value of the molar conductivity was unchanged after $24 \mathrm{~h}$, indicating that the complex is stable in solution. Elemental analysis showed that the complex contains two deprotonated H8qasesc ligands, one perchlorate anion and one crystalline DMSO molecule. Concerning all of the above-mentioned, the following formula of the novel $\mathrm{Co}$ (III) complex could be derived: $\left[\mathrm{Co}(8 \text { qasesc })_{2}\right] \mathrm{ClO}_{4} \cdot \mathrm{DMSO}$ (1). Complex 1 is diamagnetic in nature which was confirmed by magnetic moment measurement at room temperature. The structure of 1 was elucidated by spectroscopic (IR, NMR and UV-vis) and crystallographic methods. Since the ligand was obtained as a single-crystalline solid, its structure was determined by crystallographic methods also. The electrochemical behavior of the ligand and 1 was studied by cyclic voltammetry.

In the IR spectrum of 1 , shifts of $v(\mathrm{C}=\mathrm{N})$ toward higher frequencies $\left(1604 \mathrm{~cm}^{-1}\right.$ in H8qasesc and $1615 \mathrm{~cm}^{-1}$ in 1) and $v(\mathrm{C}-\mathrm{Se})$ to lower frequencies $\left(784 \mathrm{~cm}^{-1}\right.$ in H8qasesc and 761 $\mathrm{cm}^{-1}$ in 1) were noted. The same frequency shift pattern was found for the ligand Hqasesc and its Co(III) complex, which was an indication of coordination of the imine nitrogen atom and selenium atom to $\mathrm{Co}(\mathrm{III}){ }^{4}$ Also, in the IR spectrum of 1 a sharp and strong band at $\sim 1068 \mathrm{~cm}^{-1}$ originating from perchlorate ion can be observed.

The labeling of atoms in H8qasesc used in NMR is given in Scheme 1. The ${ }^{1} \mathrm{H}$ NMR spectrum of 1 (Fig. S1A, ESI shows that the nitrogen atom N3 is deprotonated as evidenced by the absence of the $\mathrm{H}-\mathrm{N} 3$ signal at $11.98 \mathrm{ppm}$ in the ${ }^{1} \mathrm{H}$ NMR spectrum of H8qasesc. Coordination via the selenium atom can be seen by the strong upfield shift of the C10 signal in the ${ }^{13} \mathrm{C}$ NMR spectrum of 1 (Fig. S1B, ESI comparison to the signal of the same carbon atom in the spectrum of metal-free H8qasesc. Coordination via the quinoline nitrogen atom can be observed by the upfield shift of $\mathrm{H}_{-}$ $\mathrm{C} 2$ and downfield shifts of $\mathrm{H}-\mathrm{C} 4$ and $\mathrm{H}-\mathrm{C} 5$ in the ${ }^{1} \mathrm{H}$ NMR spectrum of complex 1 . There is also an evidence of coordination via the quinoline nitrogen atom in the ${ }^{13} \mathrm{C}$ NMR spectrum, since signals of $\mathrm{C} 2, \mathrm{C} 4$ and C8a are shifted downfield. Coordination via the azomethine nitrogen atom can be seen by the strong upfield shift of $\mathrm{H}-\mathrm{C} 9$ in the ${ }^{1} \mathrm{H}$ NMR spectrum of the complex and by a downfield shift of C9 signal in the ${ }^{13} \mathrm{C}$ NMR spectrum of the complex. There is also an interesting correlation in the 2D ROESY spectrum of 1 (Fig. S2, ESI $\$$ ), namely $\mathrm{H}-\mathrm{C} 2$ is correlated with $\mathrm{H}-\mathrm{C} 9$ and $\mathrm{H}-\mathrm{C} 7$. This correlation points to the octahedral geometry of the complex, in which these atoms originating from two ligands are in proximity. This indicates that an octahedral geometry of the complex is preserved in the solution.

The electronic spectrum of 1 (Fig. S3A, ESI $\$$ ) exhibits four bands in the region 222-430 $\mathrm{nm}$. Three bands, at 222, 296 and $354 \mathrm{~nm}$, can be assigned to intraligand $n \rightarrow \pi^{*}$ transitions of the azomethine portion and $\pi \rightarrow \pi^{*}$ transitions of the aromatic ring, while the band at $422 \mathrm{~nm}$ was assigned to the ligand-to-metal charge transfer transition. The same number of bands and distribution of their intensities was found for a similar $\mathrm{Co}(\mathrm{III})$ complex with 2-acetylpyridine thiosemicarbazone. ${ }^{33}$ The aqueous solution behavior of 1 with respect to hydrolysis was studied in a $\mathrm{DMSO} / \mathrm{H}_{2} \mathrm{O} 1: 100(\mathrm{v} / \mathrm{v})$ solution at ambient temperature over $24 \mathrm{~h}$ by UV-vis spectroscopy. Complex 1 was stable, as can be seen from its electronic absorption spectra (Fig. S3B, ESI

The electrochemical behavior of the ligand H8qasesc and 1 was studied by cyclic voltammetry in the potential range of -2.0 to $+1.2 \mathrm{~V}$ vs. $\mathrm{Ag} / \mathrm{AgCl}$ electrode (Fig. S4, ESI clic voltammogram of H8qasesc there are four well defined oxidation peaks at potentials of $-0.382,+0.134,+0.48$ and $+0.994 \mathrm{~V}$. By reduction of H8qasesc three peaks were observed at $-0.03,-1.077$ and $-1.43 \mathrm{~V}$. From these values it could be concluded that almost all the observed peaks belong to irreversible electrochemical reactions, and only a redox couple at $E_{1 / 2}=+0.07 \mathrm{~V}$ (oxidation at $+0.134 \mathrm{~V}$ and reduction at $-0.03 \mathrm{~V}$ ) could be attributed to quasi-reversible electrochemical processes. Under the same experimental conditions, two new well-defined peaks were observed in the cyclic voltammogram of 1 . By comparison of the peak potentials one could conclude that shifts in peak positions can be 
attributed to the oxidation and reduction of electro-active groups from the ligand. Corresponding reduction peaks at -1.81 and $-1.91 \mathrm{~V}$ represent reduction of $\mathrm{Co}$ (III) to $\mathrm{Co}$ (II) and the first oxidation peak at $-1.78 \mathrm{~V}$ corresponds to the reverse oxidation process. This implies that metal ion from the complex is easily accessible at the electrode surface. All presented results were obtained after baseline background subtraction to ensure that the observed peaks belong to the redox behavior of the complex.

\subsection{Description of crystal structures}

The molecular structures and atom numbering schemes of H8qasesc and 1 are shown in Fig. 1, while Table S1 (ESI lists the pertinent X-ray crystallographic data for the two compounds. The ligand H8qasesc crystallizes in the monoclinic crystal system and $P 2_{1} / c$ space group, with four molecules in the unit cell. The selected bond lengths and angles for H8qasesc are shown in Table S2 (ESI ). The molecule of H8qasesc can be considered as planar, with the highest displacement of the $\mathrm{N} 4$ nitrogen atom $(0.084 \AA)$ from the root mean plane through all non-hydrogen atoms of the ligand. Dihedral angles (Table S3, ESI + ) confirmed the planar geometry of the molecule. The crystal packing is dominated by hydrogen bonds (Fig. S5, ESI + ).

The cobalt(III) ion coordinates two deprotonated H8qasesc ligands giving the octahedral bischelate cation $\left[\mathrm{Co}(8 \mathrm{qaSeC})_{2}\right]^{+}$ with mer geometry (Fig. 1B). In the outer sphere of the complex, there is one perchlorate ion and one DMSO solvent molecule. The sulfur atom from the DMSO molecule is disordered over two sites with occupation factors 0.88 and 0.12. Although the complex cation in 1 possesses a chiral octahedral arrangement, overall 1 is a racemic compound since it crystallizes in the centric $P \overline{1}$ space group. The deprotonated ligand coordinates the metal in a tridentate fashion by means of the selenium atom, the quinoline and the imine nitrogen atoms, forming one six-membered and one five-membered chelate rings with the essentially planar ligand skeleton. The selenium donor atoms deviate slightly from the average planes formed by the ligands' skeleton $(0.35$ and $0.19 \AA$, respectively, for Se1 and Se2). This slight distortion from planarity is due to an intramolecular repulsion between the selenium atoms which are forced by the bischelate coordination to come closer than the sum of their van der Waals radii $\left(\mathrm{Se} 1 \cdots \mathrm{Se} 2=3.358(5) \AA, r_{\mathrm{Se}}=1.90 \AA\right)$. All metal-donor atom bonds (Table S2, ESI\$) are similar to the average corresponding bonds found in a search on quinoline thio/ selenosemicarbazone-Co systems performed through the Cambridge Structural Database (CCDC: 734053; 2015 release, version. 5.36 with updates: Nov14, Feb15). ${ }^{34}$ The crystal packing of 1 (Fig. S6 and Table S4, ESI bonds involving terminal $\mathrm{NH}_{2}$ groups, deprotonated hydrazinic nitrogen atom, perchlorate ions and DMSO molecules as well as $\pi-\pi$ stacking interactions of the quinoline rings.

\subsection{Free radical scavenging activity}

Because selenium antioxidants can prevent oxidative damage, numerous animal and clinical trials have investigated the ability of these compounds to prevent oxidative stress, an underlying cause of cancer. Interest in selone $(\mathrm{C}=\mathrm{Se})$ antioxidants can be attributed to the naturally occurring selenoneine, a compound that effectively scavenges the 1,1diphenyl-2-picryl-hydrazyl (DPPH) radical. $^{35}$ In our previous study we have determined the free radical-scavenging activity of selenosemicarbazones and their metal complexes by the ABTS method. ${ }^{3}$ Our results showed that H8qasesc is an excellent ABTS cation radical scavenger, with greater efficacy than vitamin C. Coordination of the ligand to Pt(II) and Pd(II) canceled the antioxidant activity of corresponding complexes.

The proton donating ability of H8qasesc and 1 was assayed using the DPPH method, a protocol for the determination of radical scavenging activity. ${ }^{36}$ Ascorbic acid was used as the reference compound $\left(50-500 \mu \mathrm{g} \mathrm{mL}{ }^{-1}\right)$. The results
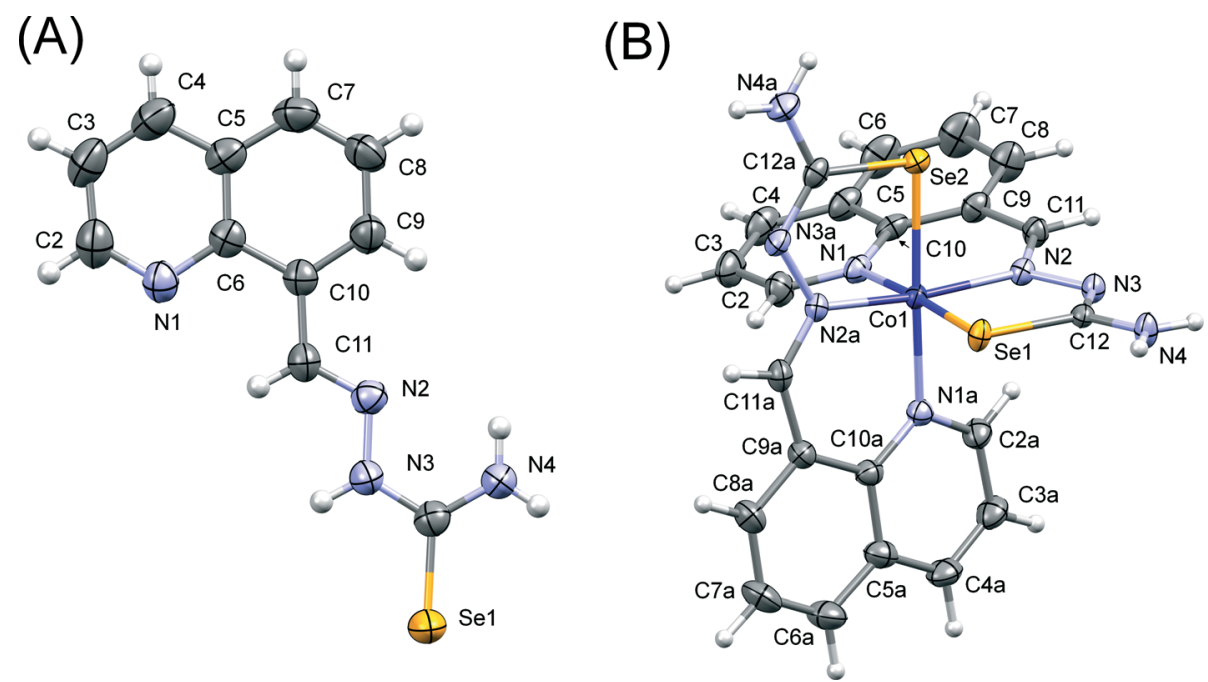

Fig. 1 Molecular structure of $\mathrm{H} 8 q$ asesc (A) and $\left[\mathrm{Co}(8 q a s e s c)_{2}\right]^{+}$(1) (B) with the non- $\mathrm{H}$ atom numbering scheme (displacement ellipsoids at $40 \%$ probability level). 

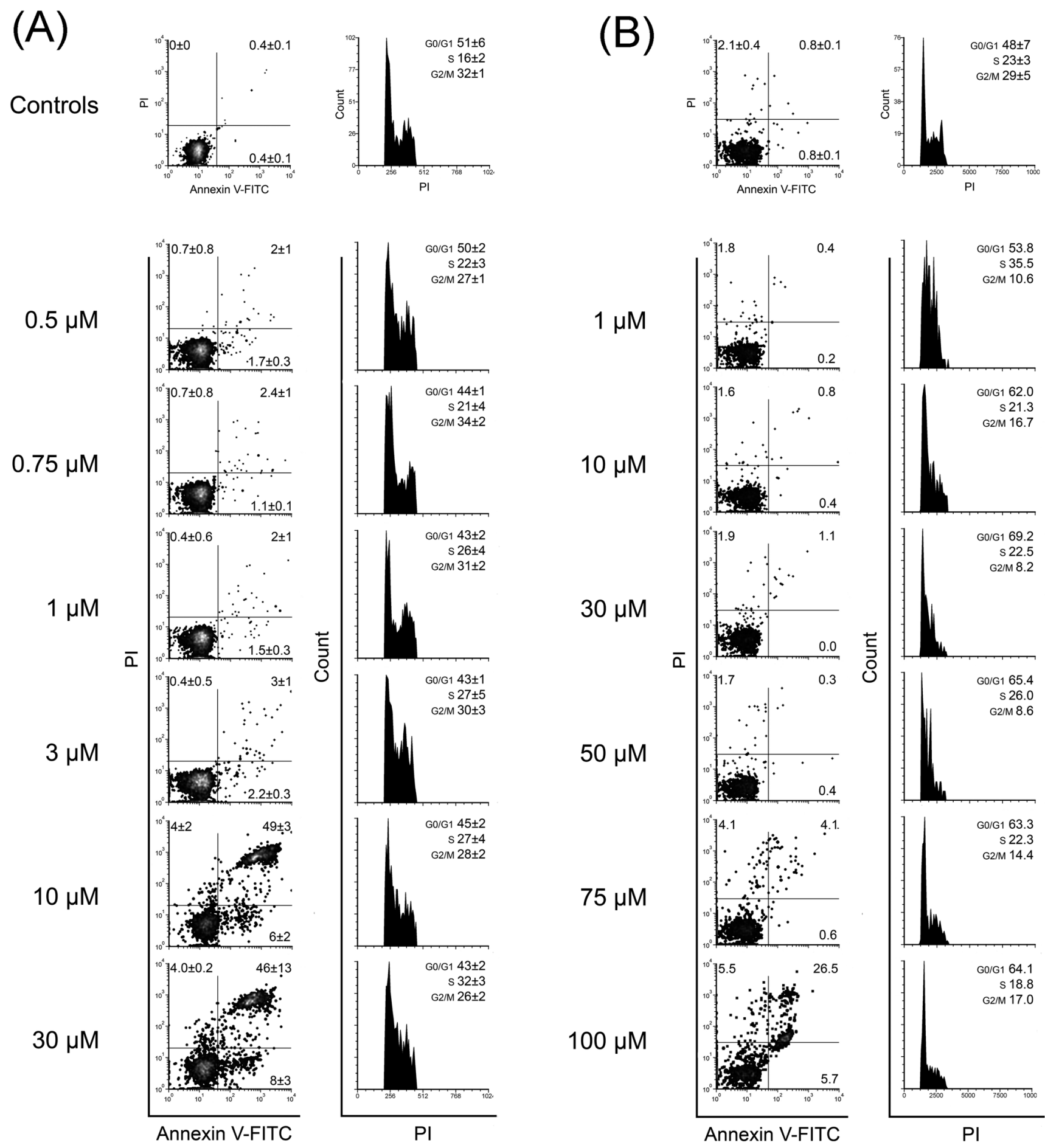

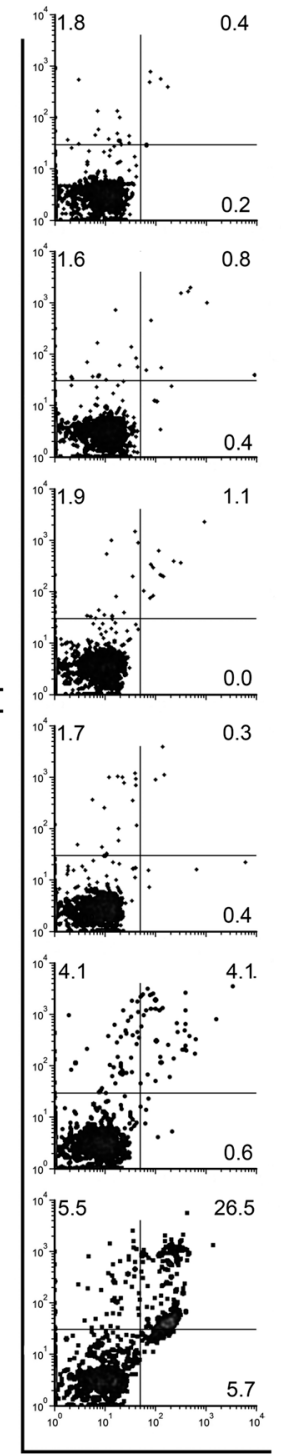

Annexin V-FITC

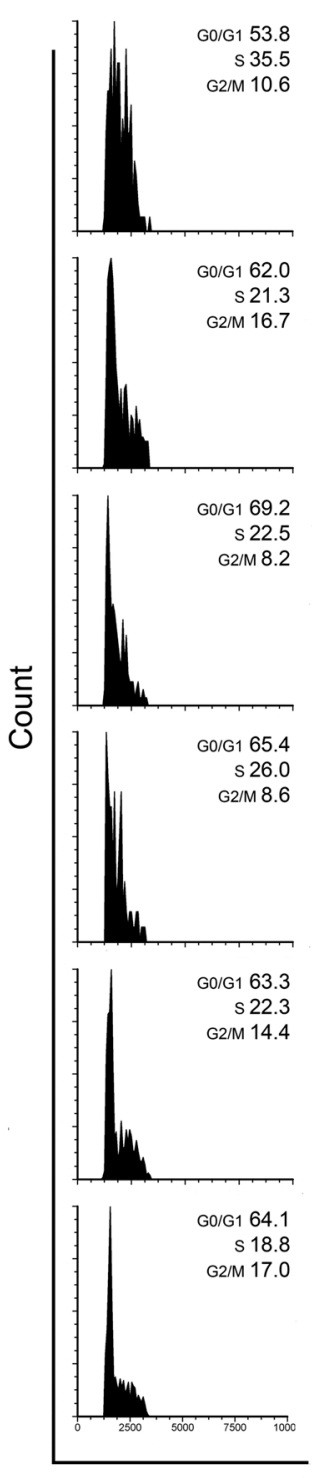

PI

Fig. 2 Activity of H8qasesc on THP-1 cells and AsPC-1 cell lines. Annexin V and propidium iodide (PI) double staining (left panels) and PI single staining (right panels) of THP-1 (A) and AsPC-1 (B) cells after $24 \mathrm{~h}$ treatment with H8qasesc applied in a range of six concentrations. In Annexin V/ PI plots cells are discriminated as viable (non-stained cells, lower left quadrant), cells in early phases of apoptosis (Annexin $V$ single stained cells, lower right quadrant), cells in late phases of apoptosis (double-stained cells, upper right quadrant), and cells in necrosis (PI single stained cells, upper left quadrant). The same cells evaluated with Annexin V/PI were fixed in ethanol right after analysis, left overnight and afterwards assayed for distribution within phases of mitotic division with the PI single staining method. The frequency of cells found in the $G_{0} / G_{1}, S$ and $G_{2} / M$ phases was determined according to the non-treated control population. All results are expressed as the mean \pm \pm SD of two replicates from independent experiments for THP-1 cells. Results for AsPC-1 cells are represented as a single replicate considering the second experiment was not performed due to low activity of H8qasesc on this cell line.

(expressed as $\mathrm{IC}_{50}$ in $\mu \mathrm{M}$ : 12.5 for H8qasesc, 5150 for 1 and 79.3 for vitamin C) corroborate our previous finding by means of the ABTS method. The ligand H8qasesc has an excellent free radical-scavenging activity, better than that of the 
reference molecule vitamin C. On the other hand, coordination of H8qasesc to $\mathrm{Co}$ (III) diminished the activity of the corresponding complex.

\subsection{H8qasesc stimulated stronger apoptotic response compared to 1 and CDDP}

The ability of H8qasesc and 1 to induce the death of THP1 and AsPC1 cells was tested in a span of six concentrations after $24 \mathrm{~h}$ of incubation. At the end of the treatment, cells were stained with Annexin V and propidium iodide (PI) in order to determine the percentages of viable and dead cells in analyzed samples. The initially applied concentration of H8qasesc on THP-1 cells in the range 1-100 $\mu \mathrm{M}$ induced an extremely high apoptotic response (data not shown), and thus these data described only the top plateau of the concentration-response sigmoidal curve while $\mathrm{ED}_{50}$ concentration could not be calculated. For this reason, concentrations of H8qasesc were decreased for THP-1 cells up to $0.5 \mu \mathrm{M}$. As represented in Fig. 2A, most apoptotic events in the samples treated with 30 and $10 \mu \mathrm{M}$ were in advanced stages of apoptosis, which means that H8qasesc easily induced cells to execute an apoptotic death. Moreover, percentages of necrotic events were barely above the control levels. Herein, the $\mathrm{ED}_{50}$ value was easily calculated and applied in all following experiments on THP-1 cells (Fig. S7, ESI + ).

Incubation with 1 induced apoptosis as well (Fig. S8A, ESI + , with some differences in response of THP1 cells therefore requiring more attention. First, percentages of apoptotic cells were gradually declining with the decrease in concentration of 1 , but even at $1 \mu \mathrm{M}$ the incidence of double stained cells was higher compared to those single-stained with Annexin V. Second, 1 also induced necrotic cell death that exceeded $10 \%$ in the samples treated with 100 and $75 \mu \mathrm{M}$ which was progressively reducing with the decrease in applied concentration, but remained persistent and surpassed $1 \%$ even at a concentration of $1 \mu \mathrm{M}$. Such a readout indicates the cellular toxicity of the investigated compound, and in order to better observe its activity profile we performed additional testing with 1 applied at lower concentrations. In the samples treated with $0.5-3 \mu \mathrm{M}$, almost the same percentages of cells in necrosis and early and late stages of apoptosis were found (Fig. S8B, ESI + ). The lack of correlation between the applied concentration of $\mathbf{1}$ and the incidence of both types of cell death in treated samples clearly signifies that 1 does not display concentration-dependent activity, but rather intrinsic toxicity. Since these results showed that 1 possesses an undesirable profile of activity, additional experiments for the second replicate have not been performed. Cisplatin (CDDP) was used as a reference compound, considering it is also a metal complex highly efficient against various types of cancer. In $24 \mathrm{~h}$ of incubation on THP-1 cells with a concentration span of 1-75 $\mu \mathrm{M}$, CDDP concentration-dependently induced an increase in the percentage of cells entering apoptotic death (Fig. S7 and S9, ESI + ). However, contrary to 1, only a small portion of apoptotic cells were conducted into ad- vanced phases of apoptosis, and as well contrary to 1, CDDP did not induce a significant increase in necrotic events.

Quite the opposite to the effect seen on the THP-1 cell line, on AsPC1 cells the ligand H8qasesc induced a noteworthy increase of apoptotic events only at the highest applied concentration of $100 \mu \mathrm{M}$ (Fig. 2B). However, some incidence of cell death was seen in the sample treated with a concentration of $75 \mu \mathrm{M}$, but those cells were either PI single-stained or double stained, while the percentage of pre-apoptotic events was on the level of the non-treated control. It is important to note that according to the control samples, AsPC1 cells contrary to the THP-1 cell line spontaneously enter necrosis rather than apoptosis; thus only a compound that acts as a strong apoptosis inducer would lead AsPC1 cells to advanced stages of apoptotic death. Considering the lack of early apoptotic events, double-stained cells in the sample treated with H8qasesc at $75 \mu \mathrm{M}$ more probably belonged to necrotic cells instead of cells in advanced stages of apoptosis ${ }^{37}$ as a result of weak pro-apoptotic stimuli. On the contrary, treatment with H8qasesc at $100 \mu \mathrm{M}$ has easily driven AsPC-1 cells from the initial to the advanced stages of apoptotic death, while a percentage of PI single-stained events remained equal to that after treatment with $75 \mu \mathrm{M}$. The estimated $\mathrm{ED}_{50}$ concentration for H8qasesc was above the maximally applied $100 \mu \mathrm{M}$, while the same could not be calculated for 1 and CDDP due to their inactivity on the AsPC-1 cell line.

\subsection{H8qasesc and CDDP induced different alterations in cell cycle distribution}

Changes in cell cycle distribution have been evaluated on the same cell populations that were previously analyzed for the pro-apoptotic activity of the investigated compounds. Considering that 1 showed an undesirable activity profile on THP-1 cells and the lack of activity on the AsPC-1 cell line, distribution within phases of cell cycle division was evaluated on cells treated with H8qasesc on both cell lines and with CDDP on THP-1 cells. The ligand H8qasesc induced a concentrationdependent accumulation of THP- 1 cells at the $S$ phase accompanied by reduced percentages of cells at the $G_{0} / G_{1}$ and $G_{2} / M$ phases (Fig. 2A). CDDP induced the accumulation of THP-1 cells at the $G_{2} / M$ phase in the sample treated with a concentration of $1 \mu \mathrm{M}$, which turned into accumulation at the $\mathrm{S}$ phase in the sample subjected to $3 \mu \mathrm{M}$, and then in a concentrationdependent manner gradually slipped at the $\mathrm{G}_{0} / \mathrm{G}_{1}$ cell cycle arrest (Fig. S9, ESI ). These results indicate that H8qasesc and CDDP exhibit different mechanisms of activity on the THP-1 cell line. In AsPC-1 cells, H8qasesc stimulated accumulation of cells at the $\mathrm{S}$ phase only at the lowest applied concentration, while an increase of its concentration arrested cell division at the $G_{0} / G_{1}$ phase (Fig. 2B).

\subsection{Apoptosis induced by H8qasesc was highly caspase- dependent but without activation of caspase-8 and -9}

To determine whether apoptosis induced by H8qasesc and CDDP was driven by a caspase-dependent pathway, we 
performed a $6 \mathrm{~h}$ treatment of THP-1 cells with H8qasesc and CDDP applied at their ED $_{50}$ concentrations, concomitantly incubated or not with pan-caspase inhibitor $N$-benzyloxycarbonylVal-Ala-Asp(OMe) fluoromethyl ketone (Z-VAD-fmk). The appropriate concentration of Z-VAD-fmk $(10 \mu \mathrm{M})$ not toxic to THP-1 cells was determined before the experiment. After incubation was ended, the treated cells were stained with Annexin V/PI, and the percentage of change in cell death events in Z-VAD-fmk co-treated cells in regard to Z-VAD-fmk non-treated cells was calculated for each labeled feature independently. As can be seen in Fig. 3, inhibition of caspase activity reduced both modalities of cell death induced by H8qasesc and CDDP. It is known that caspases have no role in the process of necrotic death, and thus the reduced percentage of PI single-stained events by Z-VAD-fmk indicates that necrotic cells recorded in ZVAD-fmk non-treated samples actually originated from cells which initially entered apoptosis. This result signifies that necrosis, although seen in a very small percentage in THP-1 cells incubated for $24 \mathrm{~h}$ with H8qasesc and CDDP, came out as a result of aponecrosis, that was inhibited by Z-VAD-fmk almost at the same percentage in the samples treated with these two compounds. However, the impact of co-treatment with Z-VAD-fmk on the process of apoptosis induced by H8qasesc and CDDP was quite different. In cells treated with H8qasesc, inhibition of caspases reduced the development of early apoptotic events for $66 \pm 16 \%$, and $29 \pm 1 \%$ of double-stained events. On the other hand, Z-VAD-fmk reduced the incidence of early apoptosis by $28 \pm 4 \%$ and $14 \pm 6 \%$ of those in advanced stages of apoptotic death in CDDP co-treated samples.

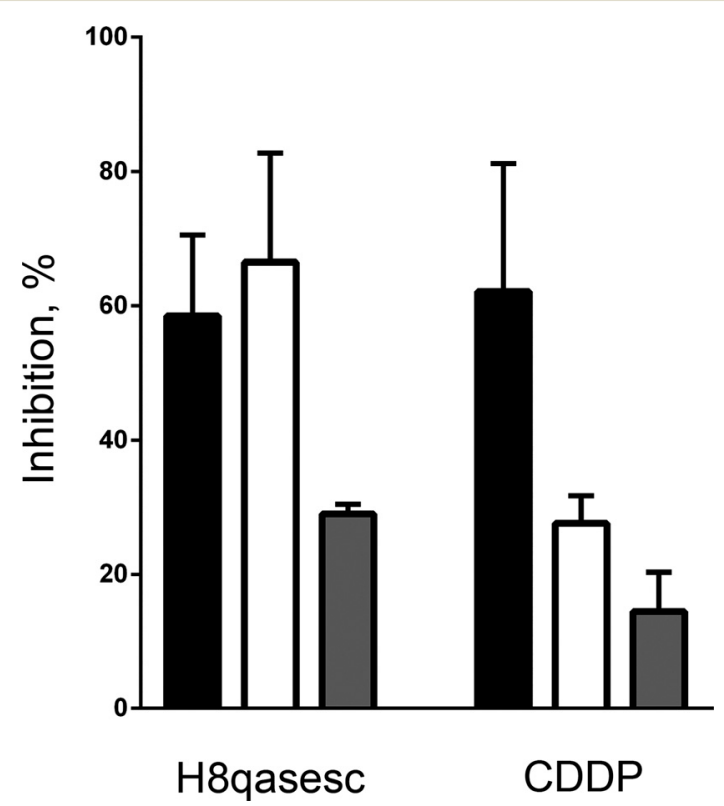

Fig. 3 Role of caspase activity in cell death induced by H8qasesc and CDDP. Percentages of early apoptosis (white bars), advanced apoptosis (gray bars) and necrosis (black bars) inhibition induced by $6 \mathrm{~h}$ of coincubation of pan-caspase inhibitor Z-VAD-fmk with H8qasesc and CDDP applied at $\mathrm{ED}_{50}$ concentrations. Results are expressed as the mean $\pm S D$ of two replicates from independent experiments.
The next step was to designate which apoptotic pathway was triggered in THP-1 cells treated with H8qasesc and CDDP. Non-treated controls and cells which underwent treatment with these two compounds applied at their $\mathrm{ED}_{50}$ concentration for $6 \mathrm{~h}$ were evaluated for caspase- 8 and -9 activities. Results of this assay should reveal whether H8qasesc and CDDP initiate apoptosis by the activation of extracellular death receptors or by an intrinsic pathway and consecutive activation of caspase-9. There was low elementary caspase- 9 activity found in control samples that points to metabolic or bioenergetic impairments as the underlying cause of spontaneous apoptosis in THP-1 cells (Fig. S10, ESI†). Treatment with H8qasesc, however, did not increase the activity of caspase- 9 compared to non-treated controls, while the activity of caspase-8 in H8qasesc-treated cells was below control levels. CDDP also induced discrete alterations in activity of evaluated caspases that may be described as a modest activation of caspase- 8 above the level seen in the non-treated control samples.

\subsection{H8qasesc can induce CSC reprogramming in AsPC-1 cells}

AsPC-1 cells were incubated for $72 \mathrm{~h}$ with or without treatment with 1 and H8qasesc applied at concentrations of 1 and $10 \mu \mathrm{M}$. Treated and non-treated cells were stained with antiCD44-FITC and anti-CD133-PE in order to evaluate possible changes in expression of these two most commonly evaluated surface markers on cancer stem cells. According to nontreated samples, AsPC- 1 cells display the $\mathrm{CD} 44^{+} / \mathrm{CD} 133^{-}$phenotype, with almost all cells positive for CD44 expression (median fluorescence intensity MFI $=3173 \pm 376$ ). Both compounds induced changes in CD44 expression in treated cells, while expression of CD133 was not affected by either of two tested treatments (Fig. 4). Incubation with 1 and H8qasesc at a concentration of $10 \mu \mathrm{M}$ gave almost the same results regarding both percent of $\mathrm{CD} 44^{+}$cells and MFI determined for the $\mathrm{CD}_{4} 4^{+}$subpopulation $(2419 \pm 235$ in 1 and $2539 \pm 185$ in H8qasesc-treated cells). However, 1 at a concentration of 1 $\mu \mathrm{M}$ induced a greater reduction in percent of $\mathrm{CD}_{4}{ }^{+}$cells, with an asymmetrical positively skewed distribution and MFI of $2637 \pm 272$. It is obvious that although treatment with 1 $\mu \mathrm{M} 1$ notably reduced the percentage of $\mathrm{CD} 44^{+}$cells, the MFI value that represents the median density of expressed CD44 per cell was higher in this population compared to the samples treated with $10 \mu \mathrm{M} 1$. However, the greatest reduction in CD44 expressing cells was achieved by the treatment with H8qasesc at $1 \mu \mathrm{M}$. This population of cells was symmetrically distributed with a significantly reduced MFI of $1800 \pm 93$ in the $\mathrm{CD} 44^{+}$subpopulation.

\subsection{Plasmid DNA interaction study}

The nuclease abilities of H8qasesc and $\mathbf{1}$ in the absence of any reducing agents were investigated using electrophoretic analysis on pUC19 plasmid incubated with increasing concentrations of the investigated compounds. As represented in Fig. 5, electrophoresis of non-treated plasmid pUC19 (lane 1 
H8qasesc

$1 \mu \mathrm{M}$
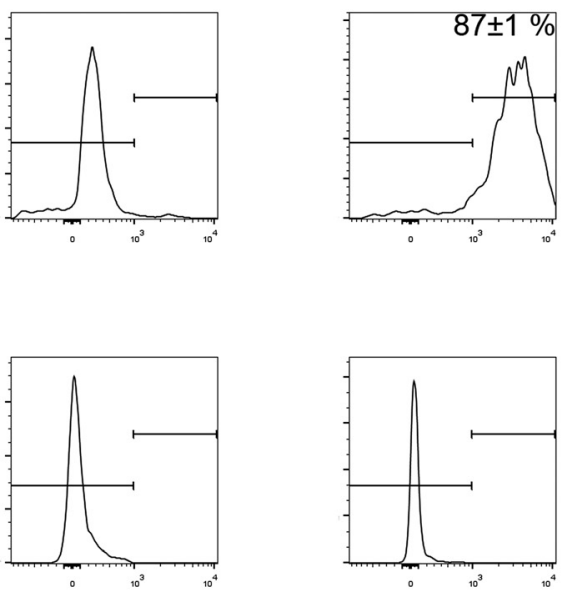
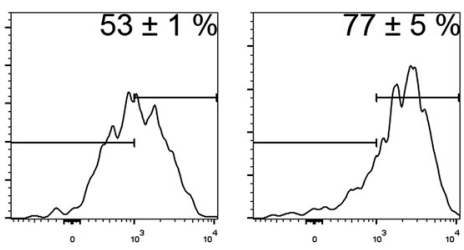

anti-CD44-FITC
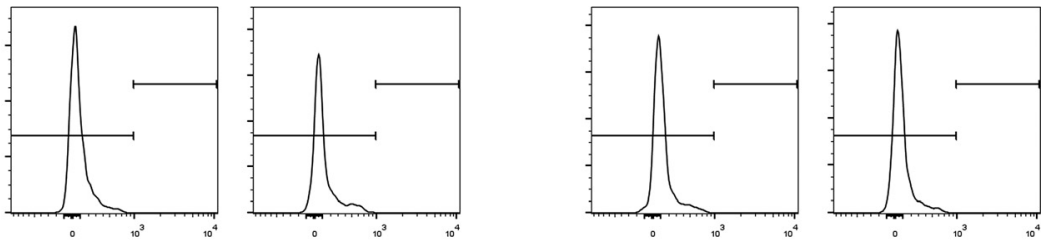

anti-CD133-PE

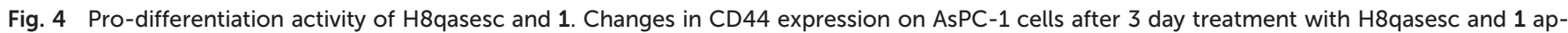

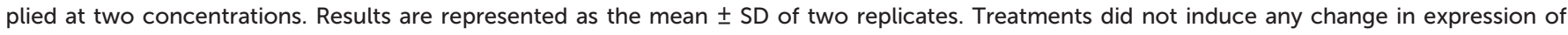
CD133.

on both gels) resulted in the formation of a strong band of supercoiled DNA (FI) and a pale band of nicked plasmid form (FII). Treatment of pUC19 with H8qasesc at the concentration range $0.125-0.875 \mathrm{mM}$ did not induce any variations in either the FI or the FII band compared to non-treated control. On the other hand, 1 applied already at its lowest concentration of $0.125 \mathrm{mM}$ induced discrete smudging but not accompanied by accelerated intensity of the FII form (Fig. 5B lane 2,). Further rise in the concentration of 1 resulted in smear formation together with gradual vanishing of the FI form. This result shows that plasmid DNA was massively concentrationdependently degraded by $\mathbf{1}$; thus the complex possesses a strong nuclease activity. Also, starting from $0.25 \mathrm{mM}$ of 1 some amount of aggregated plasmid DNA has been seen at the edge of the sample well. This aggregation might be explained by the formation of multiple hydrogen bonds between the complex cation of $\mathbf{1}$ and the phosphate moieties of plasmid DNA. Similar interactions were observed between the complex cation and the perchlorate anion in the crystal structure of 1 , since the perchlorate anion as a phosphate DNA group has a tetrahedral geometry. The aggregates were progressively fading away following the increase in the concentration of $\mathbf{1}$ most probably as a result of the nuclease activity of the complex.

\subsection{Docking studies on DNA and human serum albumin} (HSA)

Molecular docking is an extremely useful tool in drug discovery for understanding drug-biological target interactions and to investigate the potential binding mode and energy. In our docking study, to examine the binding of the ligand
H8qasesc and complex 1 to DNA, the duplex of the sequence $\mathrm{d}\left(\text { CGCGAATTCGCG) }{ }_{2} \text { (PDB ID 3U2N) }\right)^{38}$ was used. In silico molecular docking experiments revealed that the docked ligand H8qasesc showed absolute preference for minor groove binding (Fig. 6A), with binding energies in the range -27.2 to $-29.3 \mathrm{~kJ} \mathrm{~mol}^{-1}$. No intercalation positions were found. The

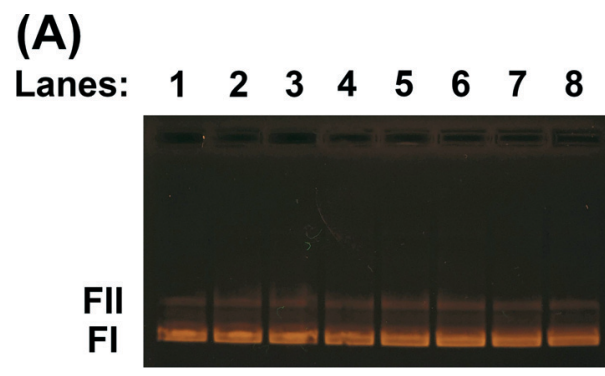

(B)

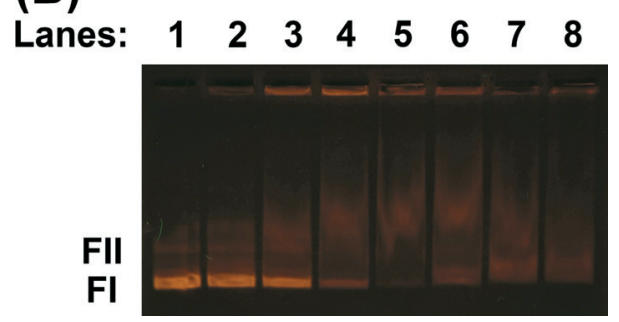

Fig. 5 Agarose gel electrophoresis of the interaction of pUC19 with H8qasesc (A) and complex 1 (B). The interactions were investigated by incubation for $90 \mathrm{~min}$ of $460 \mathrm{ng}$ of plasmid in $20 \mu \mathrm{L}$ of $40 \mathrm{mM}$ bicarbonate buffer $(\mathrm{pH} 8.4)$ at $37^{\circ} \mathrm{C}$, with different concentrations of H8qasesc and 1. Lane 1: control plasmid pUC19; lanes 3-8: pUC19 with $0.125,0.25,0.375,0.5,0.625,0.75$ and $0.875 \mathrm{mM}$ concentration of H8qasesc (A) and 1 (B). 
established interactions between H8qasesc and DNA nucleotides are hydrogen bonds (Fig. 6B). This is expected since H8qasesc consists of groups that are hydrogen bond donors (particularly $\mathrm{NH}$ and $\mathrm{NH}_{2}$ groups) as well as hydrogen bond acceptors (the quinoline nitrogen atom). On the other hand, molecular docking of 1 gave conformations binding to both minor and major grooves, with the preference for the major groove (Fig. 6C). Differences between the best docking positions in the major and minor grooves are in the range 0.418$0.836 \mathrm{~kJ} \mathrm{~mol}^{-1}$. No intercalating structures were found. Interactions of complex 1 with DNA are similar to those reported for the ligand. Additionally, aromatic systems from the coordinated ligands tend to form $\mathrm{CH}-\pi$ interactions with DNA bases (Fig. 6D).

HSA is best known for its ligand binding capacity. It provides a repository for an extraordinarily diverse range of molecules which makes it an important factor in the pharmacokinetic behavior of many drugs by affecting their efficiency and rate of delivery. ${ }^{39}$ Additionally, the feature of HSA to accumulate in solid tumors raises the interest of medicinal chemists to explore the ability of newly synthesized compounds to bind to and use HSA as a carrier, and yields the rationale for developing albumin-based drug delivery systems for tumor targeting drugs. ${ }^{40}$ Here we performed a docking analysis protocol to obtain information on the interaction of H8qasesc and 1 with HSA.

Docking of H8qasesc into HSA showed a preference for the earlier reported heme binding pocket ${ }^{41-43}$ (Fig. S11A, ESI + instead of site II near Trp 214, where 1 is found to bind (Fig. S11B, ESI + ). The calculated binding energy of $-32.6 \mathrm{~kJ}$ $\mathrm{mol}^{-1}$ suggests significant interaction of the ligand H8qasesc with HSA. Quantified interactions of 1 with amino acid residues in the binding site of HSA are given in Table S5 (ESI + ).

\subsection{General discussion}

In this work, we report the synthesis of a novel Co(III) complex with H8qasesc ligand. Both compounds were characterized with single crystal XRD. The structure of 1 in the solid state revealed that two molecules of ligand were NNSe tridentately coordinated to $\mathrm{Co}$ (III) ion. Every ligand molecule forms one 5-membered and one 6-membered chelate ring. NMR studies indicate the same coordination mode in solution.

Although the activity of the ligand on several cancer cell lines was previously investigated, due to differences in applied methodologies it is not possible to compare our current results with the previously published data. ${ }^{3}$ While colorimetric MTT assay allows the observation of reduced proliferation rates of treated cells in regard to non-treated ones, it does not provide the insight into reasons why treated cells have been decreased in number; on the other hand, Annexin V/PI double staining gives a direct assessment of the information about the magnitude and type of cell death induced. The currently applied methodological approach also includes information on cell death and cell cycle changes both gained from the very same treated cell population, giving the opportunity for an accurate observation of variations in those two parameters induced by different concentrations of investigated compounds. Therefore, instead to discuss activity of investigated compounds according to percentage of viable cells in treated samples relative to non-treated control as it is when using colorimetric assays, here we can review their profiles of activity concerning the types of cell death our compounds
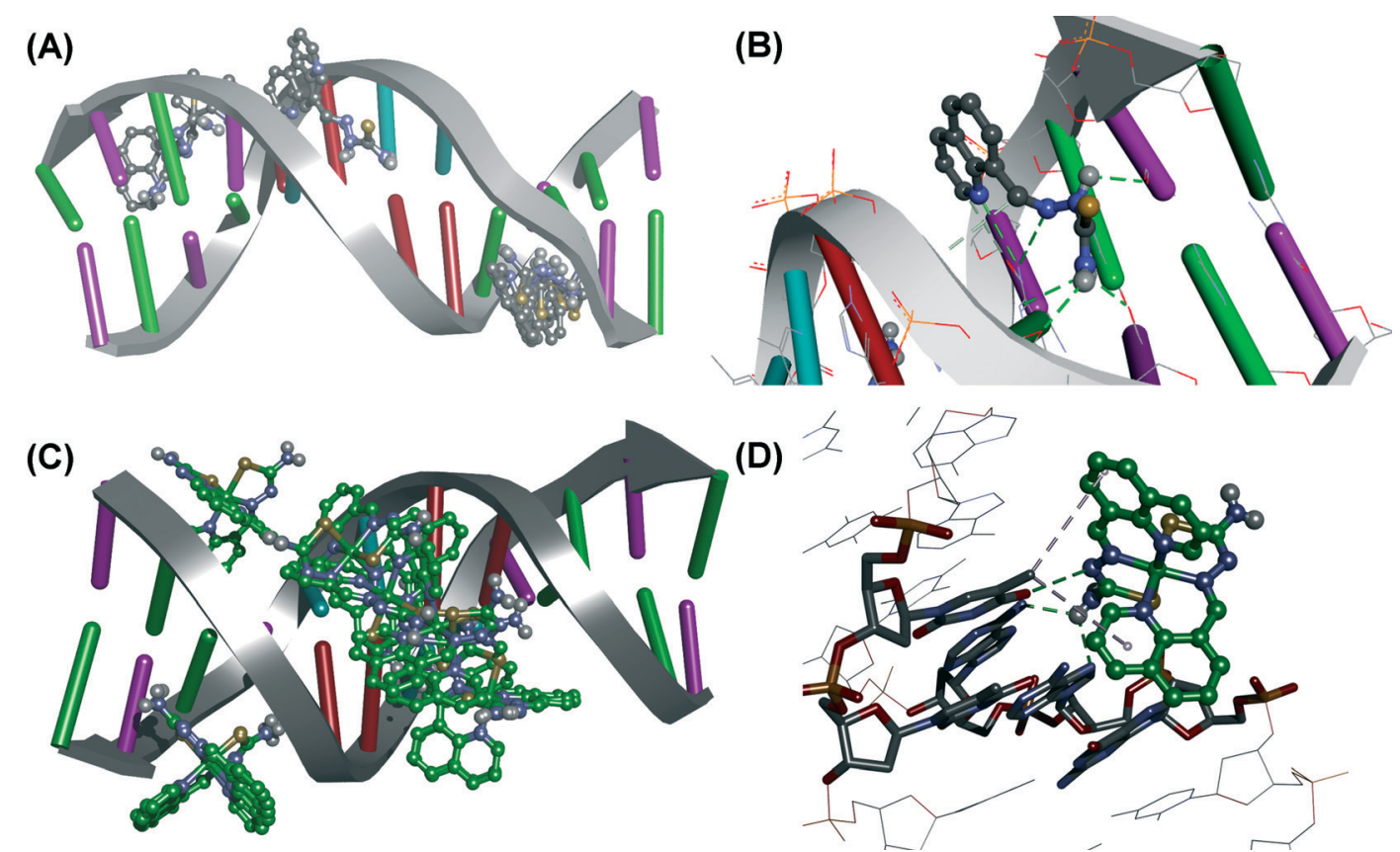

Fig. 6 (A) H8qasesc docking conformations. (B) H8qasesc - minor groove DNA marked interactions. (C) Complex 1 docking conformations. (D) 1 major groove DNA marked interactions. Dodecamer of the sequence d(CGCGAATTCGCG) 2 (PDB ID 3U2N) ${ }^{38}$ was used. Color code for interactions: green - hydrogen bonds; grey - aromatic interactions. 
induced. CDDP, H8qasesc, and 1, which we evaluated in the current study, make a perfect trio, considering that each of them illustrates a distinctive mode of anticancer activity.

CDDP, used here as a reference compound, is nowadays the most efficient metal complex for the treatment of various types of cancer. Even though the Food and Drug Administration does not approve it for the first-line treatment of acute leukemia, laboratory and clinical investigations report its ability to induce apoptosis in leukemia cells and even remission in some aggressive forms of leukemia. ${ }^{4,45}$ Current results show that CDDP concentration-dependently initiated apoptosis in the THP- 1 cell line, but almost all of the cells persisted in the early phase of apoptotic death at the end of the $24 \mathrm{~h}$ incubation period. Subsequent cell cycle analysis offered some clues to understand the reaction of THP-1 cells to the CDDP treatment. In spite of the fact that CDDP exerts various mechanisms that affect the survival of malignant cells, the most important of them is its ability to create DNA lesions. ${ }^{46-48}$ The majority of those DNA injuries are intrastrand cross-links which can be bypassed by activation of translesion synthesis polymerases during DNA replication, which are able to accommodate bulky lesions. On the contrary, interstrand cross-links, which account for a small percentage of CDDP adducts, cannot be bypassed since these cause features such as extrusion of the cytosines of the crosslink sites, bending the helix axis towards the minor groove and large DNA unwinding, ${ }^{49}$ whereas their correction involves a complex interplay between a series of DNA repair pathways. ${ }^{50}$ According to our results, accumulation of cells at the $G_{2}$ check point and the $S$ phase found in samples treated with lower concentrations were caused by obstacles during DNA synthesis, but in these samples apoptosis has not been initiated. Starting from the samples treated with CDDP at a concentration of $10 \mu \mathrm{M}$ and higher, there was a synchronized appearance of cells at the $\mathrm{G}_{1}$-to-S arrest and early apoptotic events, percentages of which were concurrently increasing in a concentration-dependent manner. It is obvious that the cells treated with CDDP at low concentrations were not halted to start DNA replication, although these were passing through the $\mathrm{S}$ phase more slowly than non-treated, undamaged cells. CDDP applied at higher concentrations obviously induced DNA damage to an extent that was increasing concentration-dependently. Therefore, these cells were arrested by activation of the $\mathrm{G}_{1}$-to-S checkpoint, which initiates a complex network of repair pathways in order to maintain genomic integrity. ${ }^{51}$ Even though it has never been demonstrated, it is logical to expect that the incidence of interstrand cross-links increases with the rise in CDDP concentration on cells. Also, it is not known for how long cells affected by CDDP treatment can remain idle at the $\mathrm{G}_{1}$-to-S arrest before apoptosis is finally initiated, but our results indicate that CDDP-treated cells, even after exposure to phosphatidylserine, delayed the execution phase of the apoptotic process for quite some time. All of these facts correspond with the relatively poor percentage of inhibited apoptosis by co-treatment with Z-VAD-fmk accompanied by a high percentage of inhibited necrosis. The lack of elevated caspase- 8 and -9 activities found after $6 \mathrm{~h}$ might be due to a short incubation time, but we previously reported that even after $24 \mathrm{~h}$ of incubation CDDP did not induce pan-caspase activation in $\mathrm{H} 460$ cells. $^{3}$

A successful anticancer agent is expected not only to elicit apoptosis but also to initiate the triggering event(s) that would drive the chains of cascaded actions within a short period of time, leading treated cells throughout the whole process of programmed cell death starting from its initiation, execution, and finally termination. Our results indicate that H8qasesc maybe meets those requirements. Contrary to CDDP, this compound is a powerful apoptosis inducer in THP-1 cells, which easily drove them throughout the course of programmed cell death. Although we do not yet have detailed knowledge about the mechanisms of H8qasesc activity on THP-1 cells, regarding the changes in cell cycle progression, H8qasesc also interferes with the process of DNA synthesis. It is important to note that the treatment with H8qasesc did not stimulate the formation of cell cycle arrest but only extended the time cells spent at the $S$ phase, which means that treated cells most probably did not activate multifaceted repair pathways. This clearly signifies that H8qasesc and CDDP do not share the same mechanism of activity. However, DNA docking analysis revealed that H8qasesc is a minor groove binder with no intercalating properties, while experimental results with pUC19 showed that H8qasesc did not display nuclease activity on plasmid DNA. On the other hand, treatment with H8qasesc also did not stimulate activation of either caspase-8 or -9 . However, results provided after co-incubation with pan-caspase inhibitor revealed that apoptosis induced by H8qasesc is highly caspase-dependent, suggesting that some caspase other than caspase-8 or -9 might be responsible for the regulation of apoptosis induced by H8qasesc. For that matter, it is very possible that caspase2 was involved knowing that it can be activated due to the formation of free radical species, DNA-damage, or cytoskeletal disruption, ${ }^{52}$ which should be further investigated. It is important to underline that the data on DNA interactions we provided here are results of the docking analysis which is theoretical approach, or were gained in cell free model that was lacking the actual nuclear milieu. Thus, our results provide information on possible H8qasesc interactions, while additional experiments on intact cells will be needed for the exact conformation of H8qasesc with its targets. Also, at this point we cannot be sure that H8qasesc does not experience structural alteration(s) due to enzymatic transformation either in serum or in targeted cells. It would be of special importance to determine the percentage of HSA occupied by H8qasesc in the human serum as well as the type of interaction, whether irreversible or competitive. These parameters will be helpful in predicting a possible effect on the transport and metabolism of heme that might be induced by treatment with H8qasesc.

Complexation of H8qasesc with Co has resulted in a compound with quite different properties. Already at the first screening on the THP-1 cell line it was obvious that 1 
displays an aggressive mode of activity, inducing necrosis and apoptosis. Its intrinsic toxicity was further confirmed in a range of several times lower concentrations. However, its $\mathrm{ED}_{50}$ value computed from one replicate, carried out on THP1 cells, is almost the same as that of H8qasesc, and more importantly it is several times lower compared to the $\mathrm{ED}_{50}$ achieved by CDDP. Considering that the aim of our investigation was to determine the ability of H8qasesc and 1 to induce apoptosis in $24 \mathrm{~h}$ with CDDP as a reference compound, H8qasesc and its Co complex might be proclaimed as very successful anticancer agents by just relying on $\mathrm{ED}_{50}$ concentrations. How actually $\mathrm{Pd}(\mathrm{II})$ and $\mathrm{Pt}(\mathrm{II})$ complexes increase the anticancer potency of H8qasesc and how these two metals significantly change the favorable mode of H8qasesc activity should be investigated in the next round, but all three metals in common drastically reduce the free radical-scavenging activity of H8qasesc. ${ }^{3}$ Additionally, we demonstrated that $\mathbf{1}$ displayed vigorous nuclease activity on plasmid pUC19, completely digesting its DNA in a concentration-dependent manner.

Results obtained on the THP-1 cell line represent the baseline evidence on the pro-apoptotic activity of the investigated compounds. Nevertheless, we were far more curious as to how the investigated compounds will affect the survival of AsPC-1 cells. As we briefly reviewed above, the AsPC-1 cell line is categorized as a CSC line. These are poorly differentiated, fast dividing, self-renewing cells, which sustain the long-term clonal maintenance of the neoplasm. CSCs are highly resistant to pro-apoptotic agents, with the unique ability to stop dividing and "hide" in a state of dormancy while escaping the harmful impact of an efficient anti-cancer agent. While neither CDDP nor 1 did induce cell death in AsPC-1 treated cells, H8qasesc generated apoptotic response at its highest applied concentration. More interestingly, only H8qasesc treatment at its lowest concentration induced accumulation of AsPC-1 cells at the $S$ phase, while in all other samples cells were arrested at the $\mathrm{G}_{0} / \mathrm{G}_{1}$ phase. Although additional experiments do remain necessary to confirm that AsPC- 1 cells are shifted into a dormant state, for example, by determining the proportion of cells within the $G_{0}$ phase by the lack of cyclin-E expression, the level of probability of dormancy rises with the fact that there was not a significant concentration-dependent variation in the magnitude of the arrest. Therefore, the $G_{0} / G_{1}$ arrest found in samples treated with H8qasesc already at a concentration of $10 \mu \mathrm{M}$ means that AsPC-1 cells were distressed but successfully resisted to apoptotic stimuli up to the concentration of $100 \mu \mathrm{M}$ when the pro-apoptotic triggering mechanism became too strong to be ignored.

CD44 is a multifunctional class I transmembrane glycoprotein involved in lymphocyte activation, recirculation and homing, adhesion of the extracellular matrix, angiogenesis, and cell proliferation, differentiation, and migration. ${ }^{53,54}$ It is also involved in numerous complex-signaling cascades, while reaction with osteoponin regulates its cellular function leading to tumor progression. Differentiation in breast CSCs by knockdown of CD44 showed a dramatically changed gene expression pattern in treated cells compared to original cells. ${ }^{55}$ Hong et al. demonstrated that $\mathrm{CD} 44^{+}$cells are responsible for the resistance to gemcitabine in pancreatic cancer. ${ }^{56}$ The same authors reported on the positive correlation between CD44 expression and histological grade and poor prognosis. All these facts clearly demonstrate the significance of CD44 down expression in AsPC-1 cells. Our results revealed that 3-day incubation with 1 achieved a percentage of $\mathrm{CD}_{4} 4^{+}$cells, but at the same time the average expression of CD44 receptors per cell in the $\mathrm{CD} 44^{+}$subpopulation was not remarkably reduced. This implies that the remaining $\mathrm{CD}_{4} 4^{+}$cells retained their phenotypic character. Quite contrarily, treatment with H8qasesc at lower tested concentrations successfully reduced the percentage of $\mathrm{CD} 44^{+}$cells together with a strikingly decreased expression of targeted protein on the membranes of the CD $44^{+}$subpopulation.

\section{Conclusion}

The activity of H8qasesc on two diverse cell lines demonstrated the ligand's ability to induce apoptotic death in more than half of treated non-CSC cells already at a concentration of $10 \mu \mathrm{M}$. This apoptotic response was shown to be highly caspase-dependent but did not include activation of either caspase-8 or -9 . In the CSC model, treatment with H8qasesc at $100 \mu \mathrm{M}$ triggered apoptosis in a highly resistant AsPC-1 cell line, while at low concentration the ligand successfully caused the change in their phenotype. Our results clearly indicate that with dose titration of H8qasesc it can be expected to achieve apoptotic death of non-CSC and CSC, or CSC differentiation, which would make them more vulnerable to pro-apoptotic drugs. In spite of our expectations, complexation of H8qasesc with $\mathrm{Co}$ (III) did not result in a compound with outstanding properties. Complex 1 displayed a strong but toxic response to the THP-1 cell line with a lack of ability to trigger death in CSCs. Its vigorous nuclease activity may be the underlying cause of the high incidence of necrosis seen in the treated samples. Finally, the excellent activity profile of H8qasesc reviewed herein deserves its further evaluation as antineoplastic agent with an expanded spectrum of actions.

\section{Acknowledgements}

The authors acknowledge networking support by the COST Action CM1106 StemChem - "Chemical Approaches to Targeting Drug Resistance in Cancer Stem Cells". The work was funded by the Ministry of Education, Science and Technological Development of the Republic of Serbia (Grant 172055).

\section{References}

1 C. Pizzo, P. Faral-Tello, G. Salinas, M. Flo, C. Robello, P. Wipf and S. G. Mahler, Medchemcomm, 2012, 3, 362-368.

2 H. G. Mautner, W. D. Kumler, Y. Okano and R. Pratt, Antibiot. Chemother., 1956, 6, 51-55. 
3 N. Filipovic, N. Polovic, B. Raskovic, S. Misirlic-Dencic, M. Dulovic, M. Savic, M. Niksic, D. Mitic, K. Andelkovic and T. Todorovic, Monatsh. Chem., 2014, 145, 1089-1099.

4 T. R. Todorovic, A. Bacchi, D. M. Sladic, N. M. Todorovic, T. T. Bozic, D. D. Radanovic, N. R. Filipovic, G. Pelizzi and K. K. Andelkovic, Inorg. Chim. Acta, 2009, 362, 3813-3820.

5 M. D. Revenko, V. I. Prisacari, A. V. Dizdari, E. F. Stratulat, I. D. Corja and L. M. Proca, Pharm. Chem. J., 2011, 45, 351-354.

6 K. Bednarz, Diss. Pharm., 1958, 10, 93-98.

7 D. L. Klayman and J. P. Scovill, US Pat., 4665173 A, 1987.

8 D. L. Klayman, J. P. Scovill, J. F. Bartosevich and J. Bruce, J. Med. Chem., 1983, 26, 35-39.

9 D. L. Klayman, J. P. Scovill, J. F. Bartosevich and C. J. Mason, Eur. J. Med. Chem., 1981, 16, 317-320.

10 J. P. Scovill, D. L. Klayman and C. F. Franchino, US Pat., 4657903, 1987.

11 K. C. Agrawal, B. A. Booth, R. L. Michaud, E. C. Moore and A. C. Sartorelli, Biochem. Pharmacol., 1974, 23, 2421-2429.

12 V. Zaharia, A. Ignat, B. Ngameni, V. Kuete, M. L. Moungang, C. N. Fokunang, M. Vasilescu, N. Palibroda, C. Cristea, L. Silaghi-Dumitrescu and B. T. Ngadjui, Med. Chem. Res., 2013, 22, 5670-5679.

13 M. Liu, P. L. Xu and Z. J. Wang, Yaoxue Xuebao, 1992, 27, 388-393.

14 V. Calcatierra, O. Lopez, J. G. Fernandez-Bolanos, G. B. Plata and J. M. Padron, Eur. J. Med. Chem., 2015, 94, 63-72.

15 D. L. Klayman, J. P. Scovill, C. J. Mason, J. F. Bartosevich, J. Bruce and A. J. Lin, Drug Res., 1983, 33, 909-912.

16 M. Zec, T. Srdic-Rajic, A. Konic-Ristic, T. Todorovic, K. Andjelkovic, I. Filipovic-Ljeskovic and S. Radulovic, AntiCancer Agents Med. Chem., 2012, 12, 1071-1080.

17 T. Srdic-Rajic, M. Zec, T. Todorovic, K. Andelkovic and S. Radulovic, Eur. J. Med. Chem., 2011, 46, 3734-3747.

18 M. Zec, T. Srdic-Rajic, A. Krivokuca, R. Jankovic, T. Todorovic, K. Andelkovic and S. Radulovic, Med. Chem., 2014, 10, 759-771.

19 S. Bjelogrlic, T. Todorovic, A. Bacchi, M. Zec, D. Sladic, T. Srdic-Rajic, D. Radanovic, S. Radulovic, G. Pelizzi and K. Andelkovic, J. Inorg. Biochem., 2010, 104, 673-682.

20 N. Gligorijevic, T. Todorovic, S. Radulovic, D. Sladic, N. Filipovic, D. Godevac, D. Jeremic and K. Andelkovic, Eur. J. Med. Chem., 2009, 44, 1623-1629.

21 A. Molter, G. N. KaluÄ‘erovï๋̈, H. Kommera, R. Paschke, T. Langer, R. PÃ $\mid$ ttgen and F. Mohr, J. Organomet. Chem., 2012, 701, 80-86.

22 C. R. Kowol, R. Eichinger, M. A. Jakupec, M. Galanski, V. B. Arion and B. K. Keppler, J. Inorg. Biochem., 2007, 101, 1946-1957.

23 H. Shen, H. Zhu, M. Song, Y. Tian, Y. Huang, H. Zheng, R. Cao, J. Lin, Z. Bi and W. Zhong, BMC Cancer, 2014, 14, 629.

24 A. Molter, J. Rust, C. W. Lehmann, G. Deepa, P. Chiba and F. Mohr, Dalton Trans., 2011, 40, 9810-9820.

25 Y. K. Bhoon, J. P. Scovill and D. L. Klayman, Indian J. Chem., Sect. A: Inorg., Phys., Theor. Anal., 1983, 22, 267-269.

26 N. R. Filipovic, S. Bjelogrlic, A. Marinkovic, T. Z. Verbic, I. N. Cvijetic, M. Sencanski, M. Rodic, M. Vujcic, D. Sladic, Z.
Strikovic, T. R. Todorovic and C. D. Muller, RSC Adv., 2015, 5, 95191-95211.

27 Z. Al-Eisawi, C. Stefani, P. J. Jansson, A. Arvind, P. C. Sharpe, M. T. Basha, G. M. Iskander, N. Kumar, Z. Kovacevic, D. J. Lane, S. Sahni, P. V. Bernhardt, D. R. Richardson and D. S. Kalinowski, J. Med. Chem., 2016, 59, 294-312.

28 V. Cracan and R. Banerjee, in Metallomics and the Cell, ed. L. Banci, Springer Netherlands, Dordrecht, 2013, pp. 333-374.

29 R. G. Matthews, Met. Ions Life Sci., 2009, 6, 53-114.

30 N. Filipovic, S. Grubisic, M. Jovanovic, M. Dulovic, I. Markovic, O. Klisuric, A. Marinkovic, D. Mitic, K. Andelkovic and T. Todorovic, Chem. Biol. Drug Des., 2014, 84, 333-341.

31 S. A. Mani, W. Guo, M. J. Liao, E. N. Eaton, A. Ayyanan, A. Y. Zhou, M. Brooks, F. Reinhard, C. C. Zhang, M. Shipitsin, L. L. Campbell, K. Polyak, C. Brisken, J. Yang and R. A. Weinberg, Cell, 2008, 133, 704-715.

32 B. Beck and C. Blanpain, Nat. Rev. Cancer, 2013, 13, 727-738.

33 R. Manikandan, P. Viswanathamurthi, K. Velmurugan, R. Nandhakumar, T. Hashimoto, A. Endo and J. Photochem, J. Photochem. Photobiol., B, 2014, 130, 205-216.

34 F. H. Allen, Acta Crystallogr., Sect. B: Struct. Sci., 2002, 58, 380-388.

35 M. T. Zimmerman, C. A. Bayse, R. R. Ramoutar and J. L. Brumaghim, J. Inorg. Biochem., 2015, 145, 30-40.

36 R. L. Prior, X. L. Wu, K. Schaich and J. Agric, Food Chem., 2005, 53, 4290-4302.

37 D. V. Krysko, T. Vanden Berghe, K. D'Herde and P. Vandenabeele, Methods, 2008, 44, 205-221.

38 D. G. Wei, W. D. Wilson and S. Neidle, J. Am. Chem. Soc., 2013, 135, 1369-1377.

39 M. Fasano, S. Curry, E. Terreno, M. Galliano, G. Fanali, P. Narciso, S. Notari and P. Ascenzi, IUBMB Life, 2005, 57, 787-796.

40 F. Kratz, J. Controlled Release, 2008, 132, 171-183.

41 M. Wardell, Z. M. Wang, J. X. Ho, J. Robert, F. Ruker, J. Ruble and D. C. Carter, Biochem. Biophys. Res. Commun., 2002, 291, 813-819.

42 P. A. Zunszain, J. Ghuman, T. Komatsu, E. Tsuchida and S. Curry, BMC Struct. Biol., 2003, 3, 6.

43 E. Tsuchida, K. Sou, A. Nakagawa, H. Sakai, T. Komatsu and K. Kobayashi, Bioconjugate Chem., 2009, 20, 1419-1440.

44 M. Previati, I. Lanzoni, E. Corbacella, S. Magosso, V. Guaran, A. Martini and S. Capitani, Int. J. Mol. Med., 2006, 18, 511-516.

45 J. LaPorte, L. Morris and J. Koepke, Case Rep Hematol, 2015, 2015, 715615.

46 R. Marullo, E. Werner, N. Degtyareva, B. Moore, G. Altavilla, S. S. Ramalingam and P. W. Doetsch, PLoS One, 2013, 8, e81162.

47 A. M. Florea and D. Busselberg, Cancers, 2011, 3, 1351-1371.

48 K. Wozniak and J. Blasiak, Acta Biochim. Pol., 2002, 49, 583-596.

49 J. M. Malinge, M. J. Giraud-Panis and M. Leng, J. Inorg. Biochem., 1999, 77, 23-29.

50 J. M. Wagner and L. M. Karnitz, Mol. Pharmacol., 2009, 76, 208-214. 
51 T. Helleday, E. Petermann, C. Lundin, B. Hodgson and R. A. Sharma, Nat. Rev. Cancer, 2008, 8, 193-204.

52 J. Puccini, L. Dorstyn and S. Kumar, Cell Death Differ., 2013, 20, 1133-1139.

53 A. Jaggupilli and E. Elkord, Clin. Dev. Immunol., 2012, 2012, 708036.
54 S. B. Keysar and A. Jimeno, Mol. Cancer Ther., 2010, 9, 2450-2457.

55 P. V. Pham, N. L. Phan, N. T. Nguyen, N. H. Truong, T. T. Duong, D. V. Le, K. D. Truong and N. K. Phan, J. Transl. Med., 2011, 9, 209.

56 S. P. Hong, J. Wen, S. Bang, S. Park and S. Y. Song, Int. J. Cancer, 2009, 125, 2323-2331. 